\title{
Pituitary surgery for small prolactinomas as an alternative to treatment with dopamine agonists
}

\author{
Muriel Babey $\cdot$ Rahel Sahli $\cdot$ Istvan Vajtai • \\ Robert H. Andres $\cdot$ Rolf W. Seiler
}

Published online: 18 December 2010

(C) The Author(s) 2010. This article is published with open access at Springerlink.com

\begin{abstract}
Despite the fact that consensus guidelines recommend long-term dopamine agonist (DA) therapy as a first-line approach to the treatment of small prolactinoma, some patients continue to prefer a primary surgical approach. Concerns over potential adverse effects of longterm medical therapy and/or the desire to become pregnant and avoid long-term medication are often mentioned as reasons to pursue surgical removal. In this retrospective study, 34 consecutive patients (30 female, 4 male) preferably underwent primary pituitary surgery without prior DA treatment for small prolactinomas (microprolactinoma 1-10 mm, macroprolactinoma 11-20 mm) at the Department of Neurosurgery, University of Bern, Switzerland. At the time of diagnosis, 31 of 34 patients $(91 \%)$ presented with symptoms. Patients with microprolactinomas had significantly lower preoperative prolactin (PRL) levels compared to patients with macroprolactinomas (median $143 \mu \mathrm{g} / \mathrm{l}$ vs. $340 \mu \mathrm{g} / \mathrm{l})$. Ninety percent of symptomatic patients experienced significant improvement of their signs
\end{abstract}

M. Babey · R. H. Andres - R. W. Seiler

Department of Neurosurgery, University of Berne,

Inselspital, 3010 Berne, Switzerland

M. Babey · R. Sahli ( $\square)$

Division of Endocrinology, Diabetes and Clinical Nutrition, University of Berne, Inselspital, 3010 Berne, Switzerland

e-mail: rahel.sahli@insel.ch

M. Babey $(\square)$

Endocrine Research Unit, Division of Endocrinology,

University of California, San Francisco, 4150 Clement Street,

San Francisco, CA 94121, USA

e-mail: muriel.babey@ucsf.edu

I. Vajtai

Institute of Pathology, University of Berne,

Inselspital, 3010 Berne, Switzerland and symptoms upon surgery. The postoperative PRL levels (median $3.45 \mu \mathrm{g} / \mathrm{l}$ ) returned to normal in $94 \%$ of patients with small prolactinomas. There was no mortality and no major morbidities. One patient suffered from hypogonadotropic hypogonadism after surgery despite postoperative normal PRL levels. Long-term remission was achieved in 22 of 24 patients $(91 \%)$ with microprolactinomas, and in 8 of 10 patients $(80 \%)$ with macroprolactinomas after a median follow-up period of 33.5 months. Patients with small prolactinomas can safely consider pituitary surgery in a specialized centre with good chance of long-term remission as an alternative to long-term DA therapy.

Keywords Pituitary surgery · Prolactinomas ·

Microprolactinomas - Macroprolactinomas ·

Prolactin · Hyperprolactinemia $\cdot$ Dopamine agonists

\section{Introduction}

Despite the fact that consensus guidelines recommend long-term dopamine agonist (DA) therapy as the first-line approach to the treatment of small prolactinomas, some patients continue to prefer a primary surgical approach because of concern over potential adverse effects of longterm medical therapy and/or the desire to avoid longterm medication [1]. Dopamine agonists (DA), especially cabergoline, is highly efficient for the treatment of small prolactinomas [2-5]. However, following the withdrawal of cabergoline treatment relapse of hyperprolactinemia has been shown in a number of studies [6-10]. Furthermore, relevant systemic side effects, including nausea, vomiting, headache, dizziness and vertigo have been reported in about one third of patients treated with DAs [1]. Recently, the increased risk of cardiac valve disease in patients 
treated for Parkinson's disease with cabergoline has raised concerns about the safety of treatment with dopamine agonists in patients with prolactinoma [11-13].

In carefully selected patients with microprolactinomas and PRL levels less than $200 \mu \mathrm{g} / \mathrm{l}$, long-term remission rates higher than $80 \%$ can be achieved with pituitary surgery [14-17]. After complete surgical resection, PRL levels return to normal, gonadal function is restored in both sexes, and the decrease in bone mineral density can be halted and reversed. A low postoperative PRL level has been shown to be the most reliable predictor of long term surgical cure [14]. The surgical techniques for pituitary surgery have been markedly improved over the last 20 years $[18,19]$. Complications from pituitary surgery for small prolactinomas are infrequent in specialized pituitary centers [14-17]. This study was performed in order to assess surgical outcomes in patients with small prolactinomas who opted for primary pituitary surgery instead of long-term therapy with DA.

\section{Patients and methods}

This retrospective study included 34 patients who underwent primary pituitary surgery without prior DA treatment for small intrasellar prolactinomas at the Department of Neurosurgery, University of Bern, between January 2003 and December 2006. The indication for first-line pituitary surgery in this study was patient's preference for surgery rather than long-term DA therapy for all patients. A microprolactinoma was defined as a tumor of $1-10 \mathrm{~mm}$; a macroprolactinoma was a lesion of 10-20 mm in diameter. Preoperative data included history and physical examination, PRL levels, and type and results of imaging studies. Other hormonal levels were not systematically evaluated in all patients and were hence not part of the analysis. The highest documented preoperative value was used as the preoperative serum level of PRL. Neuroradiological images were reviewed to exclude extrasellar extension and/or invasion of the cavernous sinuses [20]. All operations were performed by the single neurosurgeon (R.W.S.), using the transseptal, transsphenoidal microsurgical approach while the patients were in a semi sitting position [19, 21-23]. After a medial nasal incision, the septal mucosa was unilaterally detached from the cartilaginous and osseous nasal septae, respectively. A nasal speculum was inserted to keep the mucosal tunnel open. At this stage, the operating microscope was introduced and the x-ray image intensifier, also called fluoroscopy system, served for navigation and intra-operative imaging. Using the operating microscope, the vomer was exposed and opened with a drill. The septations of the sphenoid sinus were resected. Through the sphenoid sinus, i.e. transsphenoidally, the sellar floor was removed and the basal dura of the pituitary fossa was incised. Variously shaped cuvettes and micro forceps were applied to loosen and resect the intrasellar micro- or macroprolactinoma. The normal anterior pituitary gland was characterized by its yellowish color, firmer consistency and vascular surface structure and was preserved. After the microsurgical removal of a micro- or macroprolactinoma, the cavity was filled with gelatin foam soaked in fibrin glue, and the sellar opening was covered with a vicryl patch fixed with the same material. A second patch was fixed to the opening in the sella and held in place with gelatin foam and glue. Cartilage or bone was not used for reconstruction, because the package is held in place and sealed by fibrin glue. The duration of a routine pituitary operation was between 60 and $120 \mathrm{~min}$. Antibiotic treatment was started prophylactically before the operation and administered for $24 \mathrm{~h}$. Body weight, fluid intake and output, serum electrolytes, serum and urine osmolarity were monitored daily after surgery. Nasal tampons were removed on the 2 nd or 3 rd postoperative day, and the patients were discharged 3-5 days after the operation. Histopathological diagnosis was based on conventional light microscopy and specific immunohistochemistry detecting prolactin in accordance with the WHO classification of tumours of the endocrine system [24, 25]. The postoperative PRL level was determined on the morning following the surgery. Remission was defined as a normalized PRL level below $20 \mu \mathrm{g} / 1$ on the morning after surgery. A postoperative clinical, neuroradiological and biochemical evaluation was performed at 6 weeks by the operating neurosurgeon. Long-term follow-up PRL levels which were performed at the discretion of the referring physician and clinical symptoms of hyperprolactinemia were obtained by the patient's referring physician. Recurrence was defined as hyperprolactinemia $(>20 \mu \mathrm{g} / \mathrm{l})$ irrespective of the presence of symptoms and neuroradiological findings. PRL measurements were performed at different laboratories in Switzerland. Assay kits for ELISA or EIA differed between referral sources. At our institution, an electrochemiluminescence sandwich-immunoassay (Roche Modular E170, Roche Diagnostics, Mannheim, Germany) was used. The upper limit of normal for PRL was defined as $20 \mu \mathrm{g} / \mathrm{l}$. Preoperative and postoperative PRL measurements were made with the same assay kit during the study period. Data was entered into a computerized database, after which they were analyzed using SPSS 12.0 (SPSS, Chicago, IL, USA). If uniformly distributed, the data was subjected to Student's $t$ test, otherwise a Mann-Whitney test was used. The cut-off level for significance was set at $P<0.05$. Data are presented as medians, including the range and percentage, unless otherwise specified. 


\section{Results}

\section{Clinical characteristics}

Thirty four consecutive patients (30 female, 4 male) underwent transsphenoidal microscopic removal of a small prolactinoma at the Department of Neurosurgery (Table 1). Mean age at surgery was 30.4 years for women, 38.5 years for men. On the basis of magnetic resonance imaging (MRI) findings, 24 patients $(70 \%)$ had a microprolactinoma, and the remaining $10(30 \%)$ had a macroprolactinoma. At the time of diagnosis, 31 of 34 patients $(91 \%)$ had hypogonadism. Twenty eight out of 30 female patients (93\%) showed amenorrhea and/or galactorrhea. Three out of 4 male patients $(75 \%)$ complained about decreased libido and/or impotence. Two female patients (7\%) and one male patient $(25 \%)$ were asymptomatic and the adenomas were discovered by head MRI for other medical reasons. The median preoperative PRL concentration in the total cohort was $203.4 \mu \mathrm{g} / \mathrm{l}$ (range 40-1,046 $\mu \mathrm{g} / \mathrm{l}$ ). Patients with microprolactinomas had significantly lower preoperative PRL levels compared to patients with macroprolactinomas $(106.5 \mu \mathrm{g} / \mathrm{l}$ vs. $273 \mu \mathrm{g} / \mathrm{l} ; P=0.0004$, Fig. 1). Eleven of 24 patients $(45 \%)$ with microprolactinomas and 2 of 10 patients $(20 \%)$ with macroprolactinomas had preoperative PRL levels $<100 \mu \mathrm{g} / \mathrm{l}$.

\section{Early postoperative results}

Histologically all tumours were classified as prolactin cell adenomas (WHO grade I) of the sparsely granulated type. There was no evidence of invasive growth in those specimens which included fragments of dura mater. The median postoperative PRL concentration among all patients was $3.45 \mu \mathrm{g} / \mathrm{l}$ (range $0.5-23.4 \mu \mathrm{g} / \mathrm{l})$. This value was
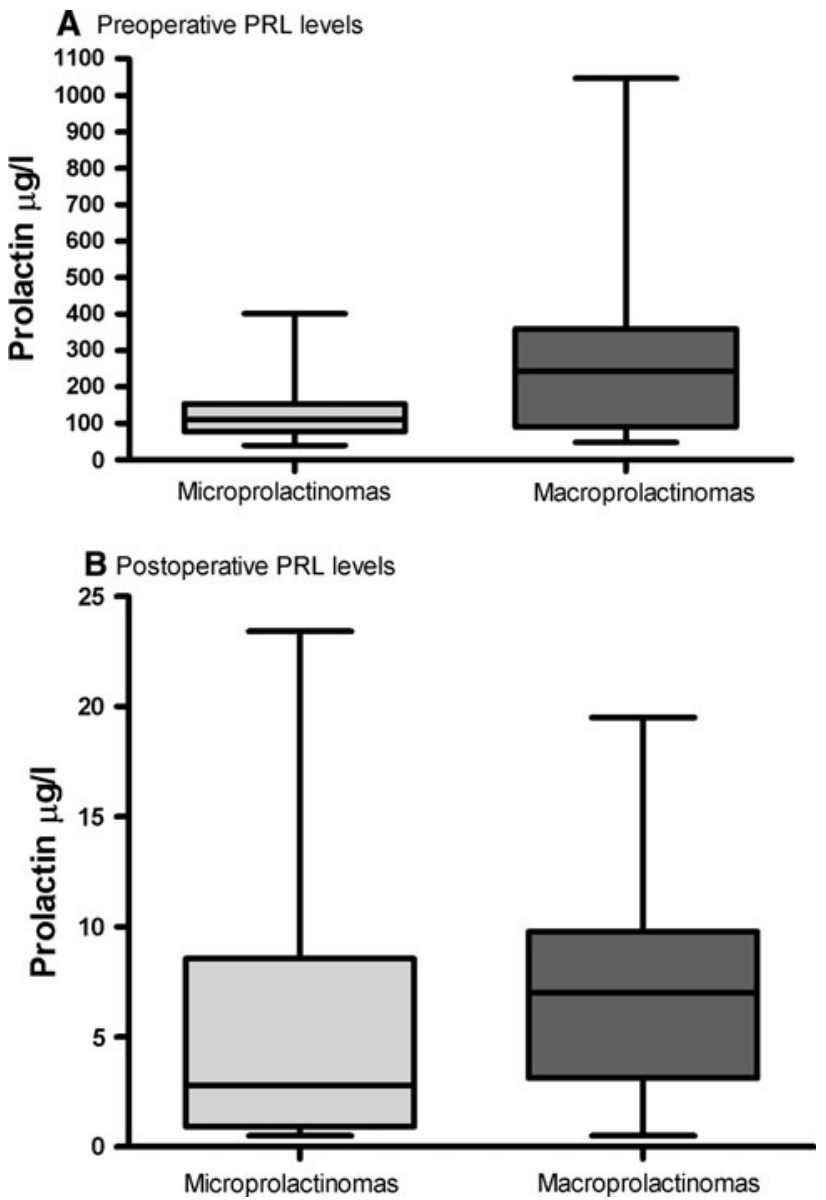

Fig. 1 Box plots (a and b) show preoperative and postoperative PRL levels in the serum for patients with micro- $(n=24)$ and macroprolactinomas $(n=10)$. The lower and upper bars in the box plots delineate the lowest and highest measured PRL level for both groups, respectively. The box contains all PRL levels from the 25th to 75th percentile. The median PRL level is shown as a line in the box. The $P$-values for the preoperative (a) and postoperative PRL levels (b) between the two groups were $* P=0.0004$ and $P=0.88$, respectively

Table 1 Characteristics of patients with micro- and macroprolactinomas

\begin{tabular}{lll}
\hline Characteristics & $\begin{array}{l}\text { Microprolactinomas 1-10 mm } \\
n=24\end{array}$ & $\begin{array}{l}\text { Macroprolactinomas 11-20 mm } \\
n=10\end{array}$ \\
\hline Age (year) & $30.2(18-52)$ & $32.6(17-57)$ \\
Female & $28.6(18-46)$ & $31.7(17-57)$ \\
Male & $38.5(18-52)$ & $\mathrm{n} / \mathrm{a}$ \\
Sex & & $10(100)$ \\
Female (\%) & $20(83)$ & $\mathrm{n} / \mathrm{a}$ \\
Male (\%) & $4(11)$ & $8(80)$ \\
Symptomatic (\%) & $21(88)$ & 8 \\
Female (Amenorrhea and/or galactorrhea) & 22 & $\mathrm{n} / \mathrm{a}$ \\
Male (Decreased libido and/or impotence) & 3 & $40.3(10-73)$ \\
Median time of follow-up (months, range) & $30.2(6-77)$ &
\end{tabular}

Data represented as median (range) and $n(\%)$ 
significantly lower than the preoperative one of $203.4 \mu \mathrm{g} / \mathrm{l}$ (range 40-1,046 $\mu \mathrm{g} / \mathrm{l}$ ). Remission, defined according to the criteria outlined in Patients and Methods was achieved in $32(94 \%)$ out of 34 patients. All 10 patients with macroprolactinomas achieved remission. Patients with microprolactinomas did not have significantly lower postoperative PRL levels compared to patients with macroprolactinomas $(2.8 \mu \mathrm{g} / \mathrm{l}$ vs. $7 \mu \mathrm{g} / \mathrm{l} ; P=0.56$, Fig. 1$)$. No operative or perioperative complications were recorded. The postoperative MRI imaging after 6 weeks showed no tumour remnants in any patients. Postoperatively, one patient had transient SIADH which necessitated rehospitalization (Table 2). One patient underwent lysis of postoperative nasal synechia. There was no mortality and no major morbidities such as new endocrinological deficits, visual loss, vascular injury or meningitis/abscess apart from one patient suffering from postoperative hypogonadotropic hypogonadism despite postoperative normal PRL levels.

\section{Long-term outcome}

Most patients experienced significant improvement of their symptoms. Twenty seven of the 30 (90\%) premenopausal women with preoperative amenorrhea resumed normal and regular menses after surgery. Two of three premenopausal women who did not resume normal menses had a recurrence of mildly elevated PRL levels $(26.8 \mu \mathrm{g} / \mathrm{l}, 46.8 \mu \mathrm{g} / \mathrm{l})$ during the follow-up. One premenopausal woman is suffering from a persistent hypogonadotropic hypogonadism despite a normal prolactin level which accounts for a new pituitary deficiency. In men, restoration of normal sexual function was reported in two out of three cases (66\%). Apart from one patient with hypogonadotropic hypogonadism, no additional patient was diagnosed with a new pituitary deficiency at postoperative or long-term evaluation. The median long-term PRL concentration in all patients was $10.95 \mu \mathrm{g} / \mathrm{l}$ (range 1.6-60.1 $\mu \mathrm{g} / \mathrm{l}$ ). Patients with microprolactinomas and those with macroprolactinomas had similar median long-term PRL levels (10.75 $\mu \mathrm{g} / \mathrm{l}$ vs. $10.95 \mu \mathrm{g} / \mathrm{l}, P=0.36$, Fig. 2). The median follow-up time period was 33.5 months for all patients (range 6-77 months). Two patients (8\%) with microprolactinomas did not achieve long-term PRL levels below $20 \mu \mathrm{g} / \mathrm{l}$ (26.8, $38.7 \mu \mathrm{g} / \mathrm{l})$. The one patient with a long-term PRL level of $26.8 \mu \mathrm{g} / \mathrm{l}$ had a preoperative PRL level that was above $400 \mu \mathrm{g} / \mathrm{l}$. For the group of 10 patients with macroprolactinomas, 2 patients (20\%) had long-term PRL levels of $46.8 \mu \mathrm{g} / \mathrm{l}$ and $60.1 \mu \mathrm{g} / \mathrm{l}$. Those two patients had preoperative PRL levels above $200 \mu \mathrm{g} / \mathrm{l}$, i.e. 360 and $466 \mu \mathrm{g} / \mathrm{l}$, respectively. Summarizing, three out of four patients with recurring hyperprolactinemia had preoperative PRL levels $>200 \mu \mathrm{g} / \mathrm{l}$ and were medically re-evaluated. Thirty patients with small sized prolactinomas (88\%) achieved long-term remission through surgical resection. Twenty two of 24 patients $(91 \%)$ with microprolactinomas and 8 of 10 patients $(80 \%)$ with macroprolactinomas are in longterm remission by pituitary surgery.

\section{Discussion}

The current management guidelines for prolactinomas [2] accept pituitary surgery as a second line treatment in nonresponders to medical therapy or in those suffering intolerance to or complications of DA. However, some patients continue to prefer a primary surgical approach because of concern over potential adverse effects of long-term medical

Table 2 Neurosurgical outcomes for patients with micro- and macroprolactinomas

\begin{tabular}{|c|c|c|}
\hline Neurosurgical outcomes & $\begin{array}{l}\text { Microprolactinomas } 1-10 \mathrm{~mm} \\
n=24\end{array}$ & $\begin{array}{l}\text { Macroprolactinomas } 11-20 \mathrm{~mm} \\
n=10\end{array}$ \\
\hline \multicolumn{3}{|l|}{ PRL level $(\mu \mathrm{g} / \mathrm{l}$, range $)$} \\
\hline Preoperative & $106.5 *(40-401)$ & $273 *(48-1,046)$ \\
\hline Postoperative & $2.8(0.5-23.4)$ & $7(0.5-19.5)$ \\
\hline Long-term & $10.75(2.6-38.7)$ & $10.95(1.6-60.1)$ \\
\hline Perioperative complications (\%) & $0(0)$ & $0(0)$ \\
\hline \multicolumn{3}{|l|}{ Morbidity } \\
\hline Postoperative transient $(\%)$ & 1 (4); SIADH & 1 (10); Nasal Synechia \\
\hline Postoperative permanent (\%) & 1 (4); Hypogonadotropic Hypogonadism & $0(0)$ \\
\hline \multicolumn{3}{|c|}{ Surgical Remission (PRL level $<20 \mu \mathrm{g} / \mathrm{l}$ ) } \\
\hline Postoperative (\%) & $22(91)$ & $10(100)$ \\
\hline Long-term $(\%)$ & $22(91)$ & $8(80)$ \\
\hline
\end{tabular}

Data represented as median (range) and $n(\%)$

* $P$-value $<0.05$ between preoperative PRL levels in micro- and macroprolactinomas 




Fig. 2 Box-plots for long-term PRL levels in the serum for patients with micro- $(n=24)$ and macroprolactinomas $(n=10)$ were obtained by the patient's referring physician after a median followup period of 33.5 months. The lower and upper bars show the lowest and highest measured long-term PRL levels for both groups, respectively. The box contains all long-term PRL levels from the 25th to 75 th percentile range. The line in the box represents the median. The $P$-value for the long-term PRL levels between the two groups was 0.11

therapy and/or the desire to avoid long-term medication use. At our institution, patients can opt for surgical resection of a small prolactinoma versus long-term DA treatment. Our overall remission rates of $88 \%$ for small prolactinomas are similar to previously reported surgical remission rates of $>90$ and $87.2 \%$ for microprolactinomas $[14,15]$ and compare favourably with the best medical remission rates after withdrawal of cabergoline in microprolactinomas [9]. Specific selection criteria for primary pituitary surgery have not been defined. A preoperative PRL level $<200 \mu \mathrm{g} / \mathrm{l}$ was a strong predictor of a surgically achieved long-term remission of hyperprolactinemia in our study. Patients with microprolactinomas and lower preoperative PRL levels than patients with macroprolactinomas $(109 \mu \mathrm{g} / \mathrm{l}$ vs. $340 \mu \mathrm{g} / \mathrm{l})$ had better remission rates (91\% vs. $80 \%$ ). A correlation of surgical high remission rate with preoperative prolactin levels was previously demonstrated in a study by Tyrell et al. $92 \%$ of the patients with preoperative PRL levels of $<100 \mu \mathrm{g} / \mathrm{l}$ and $75 \%$ of the patients with preoperative PRL levels between 101 and $200 \mu \mathrm{g} / \mathrm{l}$ experienced initial remission. However, only $37 \%$ of patients with preoperative PRL levels above $>200 \mu \mathrm{g} / \mathrm{l}$ achieved successful surgical outcomes [17]. It remains unknown, why higher PRL levels appear to be a risk factor for surgical failure for small prolactinomas [3]. Another predictor of long term surgical cure was the postoperative PRL level as demonstrated in a previous study of Amar et al. [14]. Consistent with prior findings, we found that all 22 patients (100\%) with microprolactinomas and 7 out of 8 patients $(87 \%)$ with macroprolactinomas and postoperative
PRL levels lower than $10 \mu \mathrm{g} / \mathrm{l}$ achieved long-term surgical remission. The difference in neurosurgical long-term remission rates between micro- and macroprolactinomas (91\% vs. $80 \%$ ) might suggest that complete tumour removal is more difficult to achieve with macro- than microprolactinomas.

Complications from pituitary surgery for microadenomas are uncommon. The mortality rate is typically reported as less than $0.5 \%$, while the rate of major morbidity has been cited $3.4 \%$ and includes most frequently transient diabetes insipidus, cerebrospinal fluid rhinorrhea and rarely oculomotor palsy, visual loss, stroke/vascular injury and meningitis/abscess [26, 27]. In our cohort, one patient had transient SIADH and another patient had to undergo lysis of postoperative nasal synechia. One patient was diagnosed with a new pituitary deficiency, in this case with hypogonadotropic hypogonadism after surgery which is probably explained by resecting a critical amount of pituitary gonadotropic cells surrounding the small prolactinoma. The endonasal endoscopic approach has similar complication rates compared to the traditional microsurgical technique, but less nasal traumatism, no nasal packing, less post-operative pain and usually quicker recovery have been reported for endoscopic pituitary surgery [28-30]. High surgical long-term remission rates with very low major morbidity suggest that pituitary surgery, using the traditional operating microscope in this study, can be considered an alternative and safe option in the treatment of small prolactinomas.

The surgical techniques for pituitary surgery have been refined over the last 20 years and have resulted in reductions in complication rates, particularly if the surgeon and his or her institution have sufficient experience in the field $[17,31,32]$. Many studies reporting lower surgical remission rates for prolactinomas were published more than 10 years ago. An extensive table on surgical outcomes is provided in Gillam's et al. [49] review. Recent surgical studies with similar remission and complication rates to ours were published over the last 15 years and probably demonstrate a refinement of the surgical techniques [15-17]. Recently, no study has been published including only patients preferably opting for primary surgical removal of their small prolactinoma as a first-line therapy. In the study by Kreutzer, there were 23 patients out of 212 patients analyzed who elected on a primary surgical approach. However, those patients were harboring different sizes of prolactinomas, encompassing microprolactinoma, macroprolactinoma and also giant prolactinomas and were not separately discussed in the mentioned study [15]. The study by Losa et al. also reports 21 patients (35.6\%) with microprolactinomas and 14 patients (22.9\%) with macroprolactinomas who opted for a primary surgical approach. Data for patients with small macroprolactinoma (11-20 mm) 
have not been published separately so far. Typically, those patients are included into the category of macroprolactinomas which have a much lower reported initial remission rate of $35 \%$ compared to our initial remission rate of $100 \%$ in patients with macroprolactinomas [3]. To further determine the optimal management of small prolactinomas, a large number of patients with a longer follow up, preferentially in the setting of a randomized study, need to be studied.

The recurrence rate of $8.9 \%$ in this study for patients with microprolactinomas is comparable with the recurrence rate of $5.6 \%$ for microprolactinoma reported in the study by Kreutzer et al. [15]. Losa et al. reported a recurrence rate of $16.9 \%$ in their study which was similar to most other recent surgical series [17, 32-34]. Given the median follow-up period of 33.5 months in this study, the possibility of a later recurrence of hyperprolactinemia needs to be reassessed. As shown in Fig. 3, Panel A and B the longterm PRL levels in selected patients might rise over $20 \mathrm{ng} / \mu \mathrm{l}$ over a longer follow-up period. The relapse of hyperprolactinema varied widely among different surgical series. In some studies almost all relapses occurred within the first 3 years after surgery [35-37], whereas in other studies the median time to relapse was longer than 5 years $[17,38]$. The median follow-up period of 33.5 months (range 6-77 months) in this study is therefore an important limitation, especially for patients in the shorter range of the follow-up period. The relapse of hyperprolactinemia might indicate microscopic remnants after pituitary surgery which might grow back to a tumor entity over an extended period of time. Those microscopic remnants might not be detected by postoperative MRI imaging and regular PRL levels assays over a longer-follow up period, because most small prolactinomas have very low proliferative cell indexes [39]. The study by Delgrange et al. reports only occasional Ki-67- or PCNA-positive nuclei $(<1 \%)$ in a series of 14 female microprolactinomas. In the cohort of Thomson's et al. [38] who reported 44 patients with confirmed microprolactinoma, 8 patients $(18.2 \%)$ experienced recurrent hyperprolactinemia at 2-10 years, but the elevation was permanent in only two patients. Thomson et al. concluded that the recurrence of hyperprolactinemia after pituitary surgery for microprolactinomas is not necessarily a permanent feature and does not inevitably indicate operative failure. However, we would suggest DA treatment for patients with recurrent hyperprolactinemia after a primary surgical approach if the hyperprolactinemia persists over 2 months.

Dopamine agonists have been efficient overall in the treatment of hyperprolactinemia. Cabergoline, the most effective compound, is a D2 selective agonist and induces fewer side effects than bromocriptine [40, 41]. In a high percentage of patients, PRL normalization and tumor
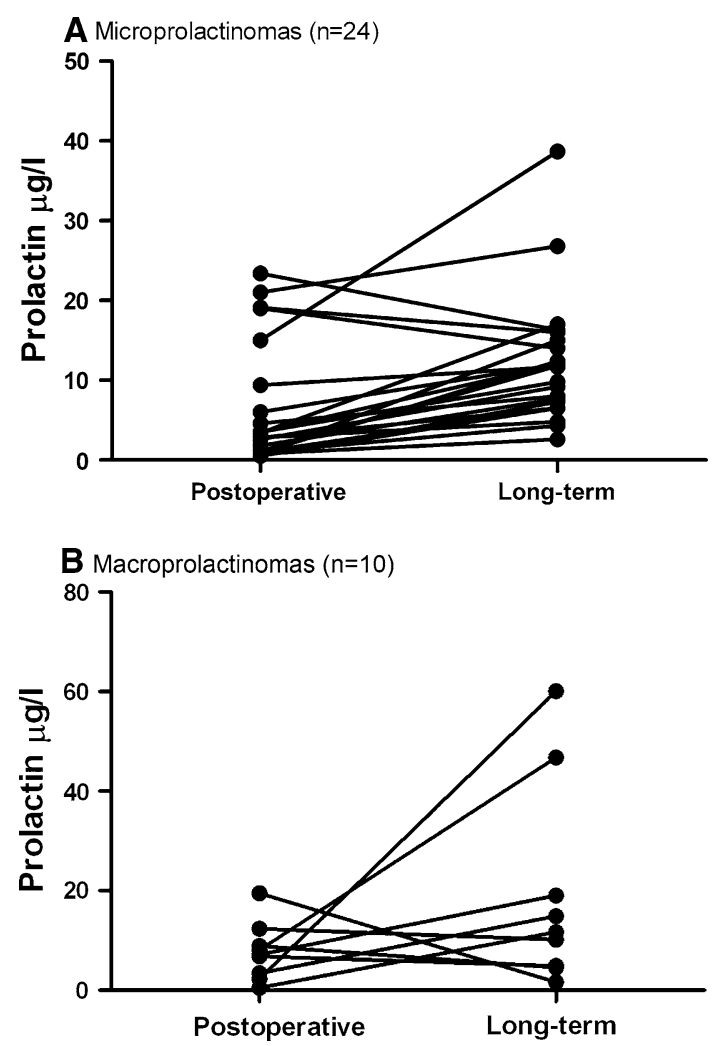

Fig. 3 Postoperative and long-term PRL levels in the serum for individual patients with small prolactinomas. a Twenty four individual postoperative and long-term PRL levels for patients with microprolactinomas. The values are shown by a black dots connected by a line. b Postoperative and long-term PRL values connected by a line for all 10 individual patients with microprolactinomas

reduction have been shown upon treatment with cabergoline in several prospective studies [7-9, 42]. For cabergoline, the most common side effects are nausea or vomiting ( $\sim 35 \%)$, followed by headache $(\sim 30 \%)$ and dizziness or vertigo $(\sim 25 \%)$ [1]. After withdrawal of cabergoline, $30 \%$ of carefully selected patients had recurrent hyperprolactinemia in a study reported by Colao et al. [9]. Patients needed to meet following criteria for discontinuation of cabergoline: normal serum prolactin levels, no visible tumor on MRI scan, or a $50 \%$ decrease or more from baseline with a tumor mass at least $5 \mathrm{~mm}$ from the optic chiasm and no evidence of cavernous sinus invasion. In the study by Kharlip et al. [10] more than half of the patients (54\%) meeting similar discontinuation criteria experienced recurrence of hyperprolactinemia within a year. In both studies, there was a strong correlation between the size of the tumor remnant and recurrence of hyperprolactinemia. In several other studies on unselected patients, even higher recurrence rates of hyperprolactinemia have been reported [6-8].

Although the side effects of dopamine agonist therapy such as nausea, headache, and dizziness are well known, 
the concern of increased cardiac valve abnormalities has recently arisen in patients with long-term DA treatment. Increased risk of valvular heart disease was first reported in patients with Parkinson's disease (PD) who were treated with very high doses of cabergoline or pergolide, showing a cumulative dose and duration effect $[11,12]$. Cabergoline or pergolide are potent serotonin $2 \mathrm{~B}$ receptor $\left(5-\mathrm{HT}_{2 \mathrm{~B}}\right)$ agonists and stimulate $5-\mathrm{HT}_{2 \mathrm{~B}}$ receptors on normally quiescent valvular cells $[43,44]$. The stimulation of $5-\mathrm{HT}_{2 \mathrm{~B}}$ receptors, which is known to activate several mitogenic pathways, appears to be a key step in initiating cabergoline-or pergolide induced valvular heart disease in patients with PD [44]. In several studies on the association between $\mathrm{PD}$ and valvular heart disease, the cumulative dose ranged between 2,600 and $6,700 \mathrm{mg}$, whereas it ranged between 200 and $443 \mathrm{mg}$ in similar studies on hyperprolactinemic patients [45]. Seven of eight observational studies on the effects of cabergoline in hyperprolactinemic patients do not show an association between cabergoline therapy and clinically relevant, i.e. moderate or severe valvular disease, whereas one study found an increased rate of moderate tricuspid regurgitation [46-51]. Within these eight observational studies, two showed an increased prevalence of mild tricuspid regurgitation [52, 53]. A recent meta-analysis by Bogazzi et al. [49] which pooled data from six clinical studies on hyperprolactinemic patients treated with cabergoline showed an increased risk of regurgitation of the tricuspid valve. One study also found increased thickening and calcifications of cardiac valves in patients treated with cabergoline compared with controls [51]. Though onset of cardiac valve disease is not associated with cabergoline treatment in patients with prolactinoma, subtle changes in cardiac valves such as calcifications, thickening and increased mitral tenting area have been observed in a subset of studies [50-52] and might predispose to more severe and clinically relevant changes in patients to whom cabergoline treatment is given long-term or in high doses.

The management of small prolactinomas in pregnant women can be complex [54, 55]. In our series no patient was pregnant, but some of the patients who opted for a primary surgical approach in this study wished to become pregnant and avoid long-term DA medication. Only a small percentage $(2.2-4.5 \%)$ of pregnant women with microprolactinomas experience a symptomatic tumor enlargement (headaches and/or visual disturbances) during gestation [56]. However, $40 \%$ of pregnant women with microprolactinomas demonstrate asymptomatic tumour growth [57]. During pregnancy, rising estrogen levels stimulates PRL synthesis and promotes lactotrope cell hyperplysia [58]. Most patients will require treatment of hyperprolactinemia to restore fertility. With a primary surgical approach, DA therapy can be avoided in a patient to restore ovulation. Therefore, the foetus is not exposed to either bromocriptine or cabergoline for at least three to 4 weeks of gestation, until a pregnancy test can verify conception and the DA medication can be discontinued. DAs are not approved for use during pregnancy. Cabergoline and bromocriptine treatment at the time of conception appears to be safe for both the pregnant patient and the neonate, showing rates of spontaneous abortions $(11 \%)$ and neonatal malformations $(3.5 \%)$ similar to those rates in normal population [57, 59-61]. However, reinstitution of the DA or surgical debunking/removal is indicated if symptomatic enlargement of a prolactinoma occurs.

\section{Conclusion}

Prolactinomas are the most common neoplasm of the anterior pituitary gland. Treatment of hyperprolactinemia is indicated because of resulting infertility, gonadal dysfunction and osteoporosis. The data presented here shows high long-term remission rates for primarily surgically treated small prolactinomas $(88 \%)$ with very low major morbidity rates in a specialized pituitary centre. Patients with small prolactinomas can therefore consider pituitary surgery as an alternative to treatment with DA. The likelihood of achieving long-term remission is high, especially if preoperative PRL levels are below $200 \mu \mathrm{g} / \mathrm{l}$. However, the possible recurrence of hyperprolactinemia after pituitary surgery needs to be addressed. Long-term DA medication and potential long-term side effects can be avoided in carefully selected patients opting for primary pituitary surgery.

Acknowledgments We would like to thank Drs. Peter Kopp, Emanuel Christ, Gordon Cutler, Luigi Mariani, Erin Gordon, Zhongjian Xie and Daniel Bikle for their helpful discussions and comments on the manuscript. This work was supported by research fellowships to Muriel Babey from Janggen-Pöhn-Foundation, Swiss National Research Foundation and Novartis Foundation.

Conflict of interest The authors have nothing to disclose and no conflict of interest.

Open Access This article is distributed under the terms of the Creative Commons Attribution Noncommercial License which permits any noncommercial use, distribution, and reproduction in any medium, provided the original author(s) and source are credited.

\section{References}

1. Molitch ME (1999) Medical treatment of prolactinomas. Endocrinol Metab Clin North Am 28(1):143-169

2. Casanueva FF, Molitch ME, Schlechte JA, Abs R, Bonert V, Bronstein MD et al (2006) Guidelines of the pituitary society for the diagnosis and management of prolactinomas. Clin Endocrinol (Oxf) 65(2):265-273 
3. Gillam MP, Molitch ME, Lombardi G, Colao A (2006) Advances in the treatment of prolactinomas. Endocr Rev 27(5):485-534

4. Dekkers OM, Lagro J, Burman P, Jorgensen JO, Romijn JA, Pereira AM (2009) Recurrence of hyperprolactinemia after withdrawal of dopamine agonists: systematic review and metaanalysis. J Clin Endocrinol Metab 95(1):43-51

5. Verhelst J, Abs R, Maiter D, van den Bruel A, Vandeweghe M, Velkeniers B et al (1999) Cabergoline in the treatment of hyperprolactinemia: a study in 455 patients. J Clin Endocrinol Metab 84(7):2518-2522

6. Biswas M, Smith J, Jadon D, McEwan P, Rees DA, Evans LM et al (2005) Long-term remission following withdrawal of dopamine agonist therapy in subjects with microprolactinomas. Clin Endocrinol (Oxf) 63(1):26-31

7. Cannavo S, Curto L, Squadrito S, Almoto B, Vieni A, Trimarchi F (1999) Cabergoline: a first-choice treatment in patients with previously untreated prolactin-secreting pituitary adenoma. J Endocrinol Invest 22(5):354-359

8. Muratori M, Arosio M, Gambino G, Romano C, Biella O, Faglia G (1997) Use of cabergoline in the long-term treatment of hyperprolactinemic and acromegalic patients. J Endocrinol Invest 20(9):537-546

9. Colao A, Di Sarno A, Cappabianca P, Di Somma C, Pivonello R, Lombardi G (2003) Withdrawal of long-term cabergoline therapy for tumoral and non tumoral hyperprolactinemia. N Engl J Med 349(21):2023-2033

10. Kharlip J, Salvatori R, Yenokyan G, Wand GS (2009) Recurrence of hyperprolactinemia after withdrawal of long-term cabergoline therapy. J Clin Endocrinol Metab 94(7):2428-2436

11. Zanettini R, Antonini A, Gatto G, Gentile R, Tesei S, Pezzoli G (2007) Valvular heart disease and the use of dopamine agonists for Parkinson's disease. N Engl J Med 356(1):39-46

12. Schade R, Andersohn F, Suissa S, Haverkamp W, Garbe E (2007) Dopamine agonists and the risk of cardiac-valve regurgitation. N Engl J Med 356(1):29-38

13. Antonini A, Poewe W (2007) Fibrotic heart-valve reactions to dopamine-agonist treatment in Parkinson's disease. Lancet Neurol 6(9):826-829

14. Amar AP, Couldwell WT, Chen JC, Weiss MH (2002) Predictive value of serum prolactin levels measured immediately after transsphenoidal surgery. J Neurosurg 97(2):307-314

15. Kreutzer J, Buslei R, Wallaschofski H, Hofmann B, Nimsky C, Fahlbusch R et al (2008) Operative treatment of prolactinomas: indications and results in a current consecutive series of 212 patients. Eur J Endocrinol 158(1):11-18

16. Turner HE, Adams CB, Wass JA (1999) Trans-sphenoidal surgery for microprolactinoma: an acceptable alternative to dopamine agonists? Eur J Endocrinol 140(1):43-47

17. Tyrrell JB, Lamborn KR, Hannegan LT, Applebury CB, Wilson CB (1999) Transsphenoidal microsurgical therapy of prolactinomas: initial outcomes and long-term results. Neurosurgery 44(2):254-261 (discussion 61-63)

18. Buchfelder M (2005) Treatment of pituitary tumours: surgery. Endocrine 28(1):67-75

19. Couldwell WT (2004) Transsphenoidal and transcranial surgery for pituitary adenomas. J Neurooncol 69(1-3):237-256

20. Cottier JP, Destrieux C, Brunereau L, Bertrand P, Moreau L, Jan $M$ et al (2000) Cavernous sinus invasion by pituitary adenoma: MR imaging. Radiology 215(2):463-469

21. Hardy J (1969) Transphenoidal microsurgery of the normal and pathological pituitary. Clin Neuro 16:185-217

22. Jane JA Jr, Thapar K, Kaptain GJ, Maartens N, Laws ER Jr (2002) Pituitary surgery: transsphenoidal approach. Neurosurgery 51(2):435-442 (discussion 42-44)

23. Buchfelder M, Schlaffer S (2009) Surgical treatment of pituitary tumours. Best Pract Res Clin Endocrinol Metab 23(5):677-692
24. Saeger W, Dea E et al (2004) Prolactin producing adenoma

25. Saeger W, Mohr K, Caselitz J, Ludecke DK (1986) Light and electron microscopical morphometry of pituitary adenomas in hyperprolactinemia. Pathol Res Pract 181(5):544-550

26. Barker FG II, Klibanski A, Swearingen B (2003) Transsphenoidal surgery for pituitary tumours in the United States, 1996-2000: mortality, morbidity, and the effects of hospital and surgeon volume. J Clin Endocrinol Metab 88(10):4709-4719

27. Sudhakar N, Ray A, Vafidis JA (2004) Complications after transsphenoidal surgery: our experience and a review of the literature. Br J Neurosurg 18(5):507-512

28. Cappabianca P, Cavallo LM, de Divitiis O, Solari D, Esposito F, Colao A (2008) Endoscopic pituitary surgery. Pituitary 11(4):385390

29. Kuroki A, Kayama T (2002) Endoscopic approach to the pituitary lesions: contemporary method and review of the literature. Biomed Pharmacother 56(Suppl 1):158s-164s

30. White DR, Sonnenburg RE, Ewend MG, Senior BA (2004) Safety of minimally invasive pituitary surgery (MIPS) compared with a traditional approach. Laryngoscope 114(11):19451948

31. Feigenbaum SL, Downey DE, Wilson CB, Jaffe RB (1996) Transsphenoidal pituitary resection for preoperative diagnosis of prolactin-secreting pituitary adenoma in women: long term follow-up. J Clin Endocrinol Metab 81(5):1711-1719

32. Webster J, Page MD, Bevan JS, Richards SH, Douglas-Jones AG, Scanlon MF (1992) Low recurrence rate after partial hypophysectomy for prolactinoma: the predictive value of dynamic prolactin function tests. Clin Endocrinol (Oxf) 36(1):35-44

33. Losa M, Mortini P, Barzaghi R, Gioia L, Giovanelli M (2002) Surgical treatment of prolactin-secreting pituitary adenomas: early results and long-term outcome. J Clin Endocrinol Metab 87(7):3180-3186

34. Rodman EF, Molitch ME, Post KD, Biller BJ, Reichlin S (1984) Long-term follow-up of transsphenoidal selective adenomectomy for prolactinoma. JAMA 252(7):921-924

35. Massoud F, Serri O, Hardy J, Somma M, Beauregard H (1996) Transsphenoidal adenomectomy for microprolactinomas: 10-20 years of follow-up. Surg Neurol 45(4):341-346

36. Schlechte JA, Sherman BM, Chapler FK, VanGilder J (1986) Long term follow-up of women with surgically treated prolactinsecreting pituitary tumours. J Clin Endocrinol Metab 62(6): 1296-1301

37. Serri O, Rasio E, Beauregard H, Hardy J, Somma M (1983) Recurrence of hyperprolactinemia after selective transsphenoidal adenomectomy in women with prolactinoma. N Engl J Med 309(5):280-283

38. Thomson JA, Gray CE, Teasdale GM (2002) Relapse of hyperprolactinemia after transsphenoidal surgery for microprolactinoma: lessons from long-term follow-up. Neurosurgery 50(1):36-39 (discussion 9-40)

39. Delgrange E, Trouillas J, Maiter D, Donckier J, Tourniaire J (1997) Sex-related difference in the growth of prolactinomas: a clinical and proliferation marker study. J Clin Endocrinol Metab 82(7):2102-2107

40. Webster J, Piscitelli G, Polli A, Ferrari CI, Ismail I, Scanlon MF (1994) A comparison of cabergoline and bromocriptine in the treatment of hyperprolactinemic amenorrhea. Cabergoline comparative study group. N Engl J Med 331(14):904-909

41. Biller BM, Molitch ME, Vance ML, Cannistraro KB, Davis KR, Simons JA et al (1996) Treatment of prolactin-secreting macroadenomas with the once-weekly dopamine agonist cabergoline. J Clin Endocrinol Metab 81(6):2338-2343

42. Di Sarno A, Landi ML, Cappabianca P, Di Salle F, Rossi FW, Pivonello R et al (2001) Resistance to cabergoline as compared with bromocriptine in hyperprolactinemia: prevalence, clinical 
definition, and therapeutic strategy. J Clin Endocrinol Metab 86(11):5256-5261

43. Jahnichen S, Horowski R, Pertz HH (2005) Agonism at 5-HT2B receptors is not a class effect of the ergolines. Eur J Pharmacol 513(3):225-228

44. Roth BL (2007) Drugs and valvular heart disease. N Engl J Med 356(1):6-9

45. Kars M, Pereira AM, Bax JJ, Romijn JA (2008) Cabergoline and cardiac valve disease in prolactinoma patients: additional studies during long-term treatment are required. Eur J Endocrinol 159(4):363-367

46. Valassi E, Klibanski A, Biller BM (2010) Clinical review\#: potential cardiac valve effects of dopamine agonists in hyperprolactinemia. J Clin Endocrinol Metab 95(3):1025-1033

47. Molitch ME (2008) The cabergoline-resistant prolactinoma patient: new challenges. J Clin Endocrinol Metab 93(12):46434645

48. Vallette S, Serri K, Serri O (2009) Cabergoline therapy for prolactinomas: is valvular heart disease a real safety concern? Expert Rev Cardiovasc Ther 8(1):49-54

49. Bogazzi F, Manetti L, Raffaelli V, Lombardi M, Rossi G, Martino E (2008) Cabergoline therapy and the risk of cardiac valve regurgitation in patients with hyperprolactinemia: a meta-analysis from clinical studies. J Endocrinol Invest 31(12):1119-1123

50. Colao A, Galderisi M, Di Sarno A, Pardo M, Gaccione M, D'Andrea $M$ et al (2008) Increased prevalence of tricuspid regurgitation in patients with prolactinomas chronically treated with cabergoline. J Clin Endocrinol Metab 93(10):3777-3784

51. Kars M, Delgado V, Holman ER, Feelders RA, Smit JW, Romijn JA et al (2008) Aortic valve calcification and mild tricuspid regurgitation but no clinical heart disease after 8 years of dopamine agonist therapy for prolactinoma. J Clin Endocrinol Metab 93(9):3348-3356

52. Lancellotti P, Livadariu E, Markov M, Daly AF, Burlacu MC, Betea D et al (2008) Cabergoline and the risk of valvular lesions in endocrine disease. Eur J Endocrinol 159(1):1-5

53. Wakil A, Rigby AS, Clark AL, Kallvikbacka-Bennett A, Atkin SL (2008) Low dose cabergoline for hyperprolactinemia is not associated with clinically significant valvular heart disease. Eur J Endocrinol 159(4):R11-R14

54. Molitch ME (1985) Pregnancy and the hyperprolactinemic woman. N Engl J Med 312(21):1364-1370

55. Molitch ME (1999) Management of prolactinomas during pregnancy. J Reprod Med 44(12 Suppl):1121-1126

56. Bronstein MD (2005) Prolactinomas and pregnancy. Pituitary $8(1): 31-38$

57. Lebbe M, Hubinont C, Bernard P, Maiter D (2010) Outcome of 100 pregnancies initiated under treatment with cabergoline in hyperprolactinemic women. Clin Endocrinol (Oxf) 73(2):236242

58. Yin P, Arita J (2000) Differential regulation of prolactin release and lactotrope proliferation during pregnancy, lactation and the estrous cycle. Neuroendocrinology 72(2):72-79

59. Colao A, Abs R, Barcena DG, Chanson P, Paulus W, Kleinberg DL (2008) Pregnancy outcomes following cabergoline treatment: extended results from a 12 year observational study. Clin Endocrinol (Oxf) 68(1):66-71

60. Molitch ME (2010) Prolactinomas and pregnancy. Clin Endocrinol (Oxf) 73(2):147-148

61. Ricci E, Parazzini F, Motta T, Ferrari CI, Colao A, Clavenna A et al (2002) Pregnancy outcome after cabergoline treatment in early weeks of gestation. Reprod Toxicol 16(6):791-793 